\title{
Pilot drug and therapeutic committee program in Sierra Leone: a descriptive mixed method study
}

\author{
John Kabba ${ }^{1}$, Mark Koroma ${ }^{2}$, Peter James ${ }^{3}$, Chenai Kitchen ${ }^{1}$, Sen Xu ${ }^{4}$, Jie Chang ${ }^{1}$, Amna \\ Saeed $^{1}$, Usman Malik ${ }^{1}$, Minghuan Jiang ${ }^{1}$, and Yu Fang ${ }^{4}$ \\ ${ }^{1}$ Xi'an Jiaotong University \\ ${ }^{2}$ Southern Medical University \\ ${ }^{3}$ University of Technology Sydney \\ ${ }^{4}$ Xian Jiaotong University
}

September 11, 2020

\begin{abstract}
Introduction Irrational medicine use is proportionately higher in low and middle-income countries like Sierra Leone. This study aims at exploring the structure, functions, and challenges of Drug, and Therapeutics Committees (DTC) recently piloted in Sierra Leone. Method A two-phase mixed-method study design was used in this study. Firstly, a cross-sectional survey using an online questionnaire to assess the structure, indicators, and challenges of DTC . In phase two, a semi-structured interview was used to get deeper insights into the key issues that emerged from the survey. Participants were mainly pharmacists in-charge at the hospitals where the DTC program hasbeen established. MS Excel 2019 and NVivo version 12 were respectively used for data management and analysis. Results DTCs mostly had a minimum of ten members consisting of a mix of both medical and hospital administrative staff. The main functions of DTC are ensuring rational medicines use, monitoring, and reporting adverse drug reactions. All but one hospital had subcommittees that are either effective or nonfunctional. The main challenges in DTC functions and maintenance were funding $(n=6)$, DTC decision implementation $(n=4)$, and unmotivated members $(\mathrm{n}=4)$. Strategies suggested to improve DTC at public hospitals and nationwide include; resource allocation, monitoring, and evaluating DTC functions and capacity building of its members. Conclusion DTC present a compelling opportunity towards achieving rational medicines use at the hospital level in Sierra Leone. Nonetheless, lack of funding, operational resources, are significant limitations. Policymakers must note these drawbacks whilst expanding DTC programs to other hospitals in Sierra Leone.
\end{abstract}

\section{What is already known about this subject}

- Drug and therapeutic committees (DTC) have been proven to be integral in medication management within health systems.

- This study gives a detail description of piloted DTC in Sierra Leone, including it structure, activities, presenting challenges and achievemenst as it strives to ensure rational use of medicines at the established hospitals.

\section{What this study adds}

- DTC provide the first documented and systematic strategy towards rational medicines use in the hospital setting in Sierra Leone.

- In a fragile and donor- driven healthcare system like Sierra Leone, DTC can be effective and achieve its purpose if operational resources are made readily available and there is technical support. 


\section{ABSTRACT}

\section{Introduction}

Irrational medicine use is proportionately higher in low and middle-income countries like Sierra Leone. This study aims at exploring the structure, functions, and challenges of Drug, and Therapeutics Committees (DTC) recently piloted in Sierra Leone.

\section{Method}

A two-phase mixed-method study design was used in this study. Firstly, a cross-sectional survey using an online questionnaire to assess the structure, indicators, and challenges of DTC . In phase two, a semistructured interview was used to get deeper insights into the key issues that emerged from the survey. Participants were mainly pharmacists in-charge at the hospitals where the DTC program hasbeen established. MS Excel 2019 and NVivo version 12 were respectively used for data management and analysis.

\section{Results}

DTCs mostly had a minimum of ten members consisting of a mix of both medical and hospital administrative staff. The main functions of DTC are ensuring rational medicines use, monitoring, and reporting adverse drug reactions. All but one hospital had subcommittees that are either effective or nonfunctional. The main challenges in DTC functions and maintenance were funding $(n=6)$, DTC decision implementation $(n=4)$, and unmotivated members $(n=4)$. Strategies suggested to improve DTC at public hospitals and nationwide include; resource allocation,monitoring, and evaluating DTC functions and capacity building of its members.

\section{Conclusion}

DTC present a compelling opportunity towards achieving rational medicines use at the hospital level in Sierra Leone. Nonetheless, lack of funding, operational resources, are significant limitations. Policymakers must note these drawbacks whilst expanding DTC programs to other hospitals in Sierra Leone.

\section{Introduction}

Irrational medicines use is a systematic and global widespread problem. The World Health Organization (WHO) estimated that more than half of all medicines are improperly prescribed, dispensed, sold, or used ${ }^{1}$. The prevalence of irrational medicines usage is comparatively higher in low and middle-income countries than in the developed world, and this is partly due to lack of robust regulatory infrastructure, high proportions of low skilled health workers, underfunding of health systems, and sporadic infectious diseases with fewer drugs options ${ }^{2,3}$. Medicines are an expensive commodity that slices up a substantial proportion of every nation's healthcare budget. However, when not correctly used this may result in unintended consequences.

Perhaps, the most significant impact of irrational medicines use is the worsening of the global antimicrobial crisis. Patients infected with resistance bacteria, for instance, have higher odds of worse clinical outcomes, exerting a significant burden on health resources ${ }^{4}$. If trends in antimicrobial resistance continue unabated, by 2050 , an estimated 10 million lives will be lost to untreated infection and at a global cost of $\$ 100$ trillion $^{5}$. To slow the antibiotic resistance epidemic, and promote rational medicine usage, the WHO and partner organizations $^{6,7}$ have been providing technical support to member states for the establishment of the Drug and Therapeutics Committee (DTC) within healthcare systems.

DTC has a broad range of functions, including; providing drug information services for medical staff, development, and monitoring of drug use policies, selection of medicines for a local formulary, and developing standard treatment guidelines (STGs). Furthermore, DTC promotes best practice in medicines use, monitor, and manage medication errors and adverse drug reactions (ADRs) ${ }^{6}$. However, country specific goals vary greatly. In a report from Australia and South Africa, the main objectives of their DTC were to ensure the optimal supply of medicines that are safe, efficacious, and cost-effective ${ }^{8,9}$. In Nigeria, hospital formulary review, surveillance of narcotics and antimicrobial use were among the primary DTC functions ${ }^{10}$. 
The epidemic of irrational medicines use is equally a significant problem in Sierra Leone and has been highlighted in previous findings. In a study involving the analysis of prescriptions form the outpatients' department (OPD), Cole et al. concluded that medicines were not rationally prescribed for children underfive as per WHO prescribing indicators ${ }^{11}$. Similar findings from a study focusing on antibiotic prescribing at a national level ${ }^{12}$ and antibiotics use for none bacterial infection, and prophylaxis ${ }^{13}$ have also been reported, which might explain the high prevalence of multidrug resistance bacteria in Sierra Leone ${ }^{14,15}$. The key reason for this trend, according to the WHO and empirical evidence, is the shortage of skilled health workers, fragility in the health system; ${ }^{16,17}$ limited diagnostics capacity in most hospitals and inadequate regulatory framework on the import and sales of pharmaceuticals ${ }^{13,17}$.

In 2016, Management Science for Health (MSH) post-Ebola recovery portfolio included catalyzing and promotion of appropriate medicines usage in Sierra Leone through the establishment of a pilot hospital DTC. The pilot program included four hospitals in Freetown, and three hospitals in the three provincials headquarter towns of Bo, Kenema and Makeni, with the prospect of adding more hospitals in the future. Currently, DTC is established in seven government hospitals across Sierra Leone. Some of the achievements include; efficient data gathering on medicines use at the hospital level and improved pharmaceutical management, thus advancing containment of antimicrobial resistance ${ }^{18,19}$. However, the specific role and responsibilities of DTC, including its membership, activities, success, and challenges, have not been reported. Such information might be essential in driving policy decisions towards the sustainability and optimization of DTC nationwide.

In this study, we aimed at evaluating the current structure, functions, activities, opportunities and challenges in the overall setup of DTC in Sierra Leone. The results are intended for formulating policy towards the improvement of DTC in Sierra Leone.

\section{Methodology}

\section{Study setting and design}

Sierra Leone has a total of 24 government hospitals distributed across its four provincial regions. The Western region harbours the largest cluster of eleven hospitals, including all the tertiary hospitals in Sierra Leone. The northern province has six hospitals whilst the southern and eastern province has four and three hospitals respectively ${ }^{20}$.

Of the seven hospitals included in the pilot DTC in Sierra Leone, four are from the Western area. They include Ola During Children's Hospital (ODCH), a specialist paediatrics hospital' Princess Christian Maternity Hospital (PCMH), a specialist obstetric and gynecologic hospital ${ }^{21}$, Connaught hospital; a general specialist hospital, and Lumley government hospital a secondary level hospital. The remaining three hospitals are from the three other provincial regions. These include Bo government hospital from the southern province, Makeni government hospital from the north and Kenema government hospital in the Eastern province

A mixed-method approach was adopted in this study, integrating both data in the result to reduce the limitation associated with a single research method ${ }^{22}$. Two sequential phases were used in the data collection process; a survey followed by a semi-structured individual interview. In phase one, an online questionnaire was used to cross-sectionally survey hospital pharmacists on the formation, activities, outputs, and challenges of their hospital DTC. In the second phase, a follow-up semi-structured individual interview was conducted to probe further into the key issues that emerged from the survey.

\section{Data collecting tools}

The online questionnaire (https://forms.gle/oKHpgKtMFGDT5LJH7) was developed using the WHO manual on DTC, ${ }^{6}$, a guide to implementing Drugs and Therapeutic Committee ${ }^{23}$, and a published systematic review involving 17 studies ${ }^{24}$. The first draft of the questionnaire was sent to two experts and a pharmacist that previously worked in a hospital with a DTC for validation, and their inputs informed the final draft used for data collection. The questionnaire has 54 items and four sections with both open and closed questions. The first section assessed respondent sociodemographic characteristics; age, gender, educational level, years 
working in the hospital, and hospital location. Section two assessed DTC membership, the professional designation of the chairperson and secretary, frequency of meetings, and the latest meeting date. Section three evaluated the key indicators of DTC with three responses, 'yes,' 'no,' and 'not sure.' Four questions in section three were about the number of meetings held in the past twelve months, the proportion of members that regularly attend meetings, the number of ADR recorded, and the policy decisions taken during that period. The last question within the section rated the effectiveness of the DTC on a scale of 1 to 10 . The fourth section evaluated the challenges of DTC with 'yes,' 'no' and 'not sure' responses and a follow-up question to give details explanations if the response is 'yes.'

The semi-structured interview guide was developed based on the results of the questionnaire survey. It included eight questions, ranging from membership to DTC, training of members, DTC subcommittee functions, ADR reporting, drug use policies, and challenges within local DTC. See details in Appendix 4.

\section{Sampling and data collection}

The pilot DTC program was established in seven hospitals across the country. We purposively recruited pharmacists who have been working in those hospitals for both the questionnaire survey and the individual interview. Pharmacists were targeted as they were vital in the pilot program and attended most of the DTC workshops conducted by MSH. They are also the secretary of DTC and servers to coordinate DTC activities, contribute to the formulation and Implementation of local drug use policies.

In each of the seven hospitals, the pharmacist-in-charge or a pharmacist who has been working at the hospital for the past 12 months leading to April 1, 2020, was contacted via WhatsApp massaging app a social media application that is getting popular in medical education and communication ${ }^{25}$, 26 . The lead investigators relayed detailed explanations of the research through text messages, voice notes, WhatsApp call, or a combination of these methods. A link to the online questionnaire (google form) was then sent to the WhatsApp number of all selected pharmacists that consented to participate in the study. A reminder message was sent to all participants at the end of each week from April 1 to April 21, 2020, the respective start and end date of the survey data collection.

Interviews were conducted using WhatsApp call feature or voice message when necessary after the analysis of the survey data. Similarly, participants were recruited using WhatsApp messenger, and a convenient time for the online interview was scheduled. All interviews were conducted in English between May 10 and June 2 2020, and the conversations were recorded using a voice recorder.

All participants in this study were given a token of $\$ 10$ as a motivation for their time and to help cover mobile data charges they would have incurred.

\section{Ethical consideration}

The Sierra Leone Ethics and Scientific Review Committee of the Ministry of Health granted ethical clearance. All participants consented to take part in the study, and due to the small sample size, pharmacists and hospitals were anonymized in the results.

\section{Data analysis}

Survey data was exported to MS Excel for analysis. Categorical and continuous variables were analyzed descriptively. Response to open questions were coded according to the themes that emerged and quantified.

Interviews were transcribed verbatim in MS word, in instances where discrepancies arose, the individual interviewee was contacted on WhatsApp for clarification. Following an inductive analytical approach, the transcripts were thoroughly read by the two lead authors, the text condensed into themes, and further categorized into general and subthemes ${ }^{27}$. Other members of the research team reviewed the results from the two leading authors, and a consensus on the themes was met, which inform the final result. Data management and analysis were done using NVivo version 12 .

\section{Results}




\section{Characteristics of hospital and respondents}

There are seven hospitals with established DTC (pilot program) in Sierra Leone, the majority are in Freetown $(n=4)$, and the rest are distributed within the other three regions in Sierra Leone. Except for Kenema government hospital, all other hospitals have at least two pharmacists. All hospitals in which DTC is piloted had a participant that responded to the questionnaire, was interviewed, or both. Summarized in Appendix 1

Six pharmacists, one each from the six different hospitals with DTC, responded to the questionnaire. Most were male $(n=5)$ and had been working at their respective hospitals between 1-3 years $(n=4)$. Three out of five pharmacists interviewed were from Freetown. (Appendices-2 and 3)

\section{Membership of DTC in Sierra Leone and their specific functions}

In the formative stage of DTC, training workshops were organized for key medical, pharmacy, and nursing staff of the seven hospitals selected in the pilot program. Following the training of these healthcare staff, local DTCs committees were set up in each of the seven healthcare facilities.

Table-1 summarises the membership of DTC in the different hospitals. Each has at least ten members except secondary hospital 1. DTC membership composed of a representative from each of the departments in the hospital, although priority was given to healthcare staff directly involved in the medication use process, and key decision-makers such as the hospital secretary and matron. Almost all hospitals have at least two pharmacists, three doctors, a nurse, a microbiologist, a community health officer $(\mathrm{CHO})$, and a representative from the hospital administration as members of their DTC.

In establishing membership within our hospital, our target was to have a representative from each of the units at the hospital with a target of getting at least ten members [Pharmacist Tertiary Hps 2].It [DTC membership] must involve all those that deal with medicines and does clinical work within the hospital. Hence, prescriber, dispenser, those who handle and administer or being involved in any therapeutic functions which incorporate professionals like nutritionist can be members. [Pharmacist Tertiary Hps 1] We have a representative from internal medicines and all the sub-clinical units because they are prescribers. We also included the hospital secretary and matron, because they are vital administrators who influence the decision-making process in the hospital [Pharmacist Regional Hps 1]

\section{Main functions of DTC}

Accordingly, the main functions of DTC are ensuring rational medicines use at the hospital level, monitoring and reporting ADRs/ADEs, antimicrobial stewardship, and providing drug information support to medical staff. Four hospitals extended DTC functions to include preventing drug shortages while only one of the regional hospitals engaged in drug procurements processes. Table 2

In my hospital, the functions of DTC also include making drug procurement recommendations, especially antibiotics. This is because we know the disease patterns locally and can, therefore, recommend the most effective antibiotics to procure [Pharmacist Regional Hps 1]

\section{DTC indicator}

As listed in table 3, virtually all hospitals local DTC have a stated mission and an annual plan, which includes capacity building and continuous professional education. Five of the hospitals' DTC acknowledges

having a well-established standard guideline for DTC operations. Subcommittees are present in all hospitals except one; however, not all were effective according to the account of some of the pharmacists interviewed.

We have two sub-committee ADR and antimicrobial stewardship committee [Pharmacist Tertiary Hps 1]So far, there are sub-committee on antibiotics stewardships; however, none of those committees is functional. [Pharmacist Tertiary Hps 2]The ADR committee members are mainly tasked with the responsibility of circulating ADR forms in collaborations with the Pharmacy Board of Sierra Leone (PBSL) pharmacovigilance 
departments, who also monitors ADRs. The antimicrobial stewardship committee ensures the rational use of antimicrobial agents within the hospital. [Pharmacist Tertiary Hps 1]

DTC meetings are usually held monthly (three hospitals) or quarterly (3 hospitals), and more than 50\% (five hospitals) of DTC members do attend. However, there are instances of low meeting turnout (one hospital) due to members being busy with other functions. As one participant puts it, low meeting turnout tends to give the impression that DTC is not critical in ensuring the rational use of medicines, and in improving patient health outcomes.

The chairperson of DTC seems very busy with other tasks in the hospital. He is absent for most meetings. Even though that does not stop the meetings from going on, it gives the impression that DTC is not a priority at our hospital. [Pharmacist Tertiary Hps 2]

DTC effectiveness measured on a 1-10 scale, in which 1 and 10 represent least and most effective respectively. The result (in table 3 ) shows that effectiveness ranges from not effective (1/10) reported in one hospital to very effective (8/10). Three out of six hospital DTCs' reported being averagely effective $(5 / 10-.6 / 10)$.

\section{Drug use policies introduced by some hospital DTC}

Table 4 summaries some medicines use policies introduced by hospital DTC. Drugs such as Paracetamol tablets, Nystatin syrups, and antimalarials were observed from routine drug use evaluations to be irrationally prescribed, dispensed and administered to patients

Paracetamol was observed to be given as an incentive to encourage antenatal clinic attendance. Nystatin syrup was sometimes given to neonate with white patches in their mouth and amoxicillin to patients with signs of upper respiratory infection, without laboratory evaluation or specialist clinician recommendations. Also, antimalarials were prescribed for patients with fever irrespective of cause without laboratory evaluation for definitive diagnosis. This led to the introduction of local policies to reduce such practices.

The use of antimalaria, testing should be done before initiating antimalaria medication and antibiotics must be prescribed rationally [Pharmacist Tertiary Hps 3]

Non-standard prescription writing, which has tendencies to cause medication errors was also a common practice; local policies were introduced to prevent or reduce such occurrence.

The policy [on prescriptions] informs prescribers about the standard writing format of all prescriptions; this prevents non-professional from writing prescriptions as it used to be in the past.... the policy dictates all prescriptions must come from professionals with the legal framework to prescribe. [Pharmacist Tertiary Hps 1]Prescribers, which includes doctors, and CHOs, they have to adhere to the set standards when writing prescription failure to do so will render a prescription invalid. The policy also guides on the number of drugs that should be on a prescription at the outpatients' departments. Also, when prescribing for children, their weight should be written on the prescription's leaflets. This is important in that if the prescriber did not calculate the actual dosage of the patients, the pharmacist would rectify that at the dispensary. The introduction of these policies saw a reduction of possible errors, ADRs, and there was a substantial reduction in wastage of drugs [Pharmacist Tertiary Hps 1]The introduction of such policies has tremendously changed the situation of irrational drug use, especially for antibiotics. We use to having some prescribers prescribing three to four antibiotics on one prescription but not now [Pharmacist Tertiary Hps 3]

\section{Challenges in functioning and maintaining DTC}

Table 5 summaries the respondents' challenges in maintaining DTC functions. All survey respondents, highlighted funding $(\mathrm{n}=6)$ as their main challenge in maintaining DTC functions. Other challenges are implementing DTC decision $(\mathrm{n}=4)$, and unmotivated DTC members $(\mathrm{n}=4)$.

Concerning funding, at any time we present our annual budget for running DTC to the MoH, it never gets approved, so that has been a serious challenge [Pharmacist Regional Hps 1]No logistical support at the moment or financial support, also people [from $\mathrm{MoH}$ ] do not come around to check and provide support, 
that is demotivating [Pharmacist Regional Hps-2]Hospitals do not want to capture DTC in their annual budget planning; some [Hospital management] will tell you, probably they make the budget plan, but the funding allocations did not come on time, so these constraints are common. Holistically, the main problem is resources allocation; if they are made available, then members will be motivated [Pharmacist Tertiary Hps-1]

Lack of technical competence $(n=3)$ in the functions of DTC and interest $(n=3)$ were also reported as challenges summarized in table- 5 .

Another challenge is that members need technical training to enhance their competence in the activities of DTC [Pharmacist Regional Hps-1]

\section{Strategies towards improving DTC suggested by pharmacists}

The three major subthemes that emerged from interviewing pharmacists on strategies to improve DTC in their hospital and nationally, includes, resources availability, monitoring and evaluation of DTC activities, and capacity building for DTC members

Pharmacists suggested that the allocation of DTC specific resources, which include but not limited to financial resources, will promote the optimal functioning of DTCs functions in Sierra Leone.

let the MoH capacitate the Directorate of Drug and Medical Supply by providing them with all the resources and necessary equipment's needed to achieve that goal (optimal DTC functionality) [PhmTertiaryHps-1]The hospital management need to include in their annual budget funding for DTC activities because for now we have funding from the $\mathrm{MoH}$ and donor partners, but what if they stop, automatically the DTC will stop functioning [Pharmacist Tertiary Hps-3]Funding is not only limited to financial resources by all necessary inputs like computers, stationery, printers, and even internet connectivity should be provided [Pharmacist Regional Hps-1]

Also, effective monitoring and evaluations of DTC functions and activities were suggested as another measure to improving DTC functioning in Sierra Leone.

The focal person at MoH should follow-up on hospital-specific progress routinely, which would serve as a motivation for us to be serious about DTC. This is important because in our hospital there are lots of other committees in which we are also engaged in [Pharmacist Tertiary Hps-2]Periodic checks on the progress of DTC by MoH officials will also serve as motivation. For example, we once had a representative from WHO and the National Chief pharmacists attending our DTC meeting. Their presence that servers as a motivation for many, and it also affirms the importance of DTC to individuals who might not want to take it seriously. [Pharmacist Tertiary Hps 1]Lastly, pharmacists recommended that, as part of the capacity building strategy, the current drafted DTC operational manual should be rectified and implemented. They also suggested that DTC members should have access to various educational materials such as newsletters, research articles in order to build capacity, which would improve their output in the DTC.Also, the DTC operational manual should be effected because the one drafted had not been rectified for use. [Pharmacist Tertiary Hps-1]Educational materials like newsletters or recent developments in DTC are also necessary for capacity building. Information sharing about DTC functions and activities withing Sierra Leone and internationally will serve as motivation [Pharmacist Regional Hps 1]

\section{Discussion}

This study presented a detailed and comprehensive overview of the DTC program that was piloted in Sierra Leone, and included details of structure and membership, key indicators and activities, challenges, and improvement measures. The findings are integral towards developing and understanding the framework of activities and challenges facing such programs and ways to consolidate them while expanding DTC nationally. It also provides a reference point and baseline data for healthcare professionals and policymakers involved in rational medicines user-related activities in Sierra Leone and other countries within the sub-region.

Membership 
Unlike in other settings ${ }^{28-30}$, as this was a pilot program ,DTC membership in Sierra Leone is mainly homogeneous and identical across all the hospitals studied. It is dominated by medical staff ${ }^{31}$, including doctors, pharmacists, nurses, laboratory technicians, and CHO, but also included administrative personnel. The representation of medical staff is similar to DTC in Brazil ${ }^{28}$, Nigeria ${ }^{10}$, and in Danmark ${ }^{30}$, but it is not as complex as in Spain ${ }^{32}$ and Jordan ${ }^{29}$. According to the $\mathrm{WHO}^{6}$, the interprofessional mix is essential for the successful and effective functioning of the DTC and the implementation of key policies. Furthermore, it provides an opportunity for the interaction of multidisciplinary medical personnel and hospital administrative staff, this allows for a multidimensional perspective towards medicines use discussion and policies ${ }^{33,34}$. The role and responsibilities of members in the DTC are critical towards its success. In this current study, the hospital medical superintendent, and pharmacist-in-charge are respectively the chairperson and secretary as recommended by the $\mathrm{WHO}^{6}$. Similar DTC setups have been reported in hospitals in Nigeria ${ }^{10}$. This structural make-up is very common, but instances have also been reported in which a pharmacist acts as chairperson, and in some settings, pharmacists are excluded as DTC members depending on the scope, aims and objectives of the DTC and availability of pharmacists ${ }^{29,31,35}$.

Functions of DTC

The scope and framework of DTC's primary functionality are dynamic and differs significantly according to settings and, in some cases, the hospital type. In his review, Mikael Hoffmann gives a vivid account of the change in scope of DTC over time in different countries, from logistics solutions to cost-effective analysis and a focus on patients' safety ${ }^{36}$. The WHO manual also detailed DTC functions ${ }^{6,7}$; however, it advises on adapting DTC aims and objectives as per local needs. In Sierra Leone, DTC functions are centered around rational medicine use and audit on patient's safety at the hospital level. Only one hospital extended the scope of its function to include drug procurements. These findings are similar to a study from South Africa 37 , Jordan ${ }^{29}$, but differ from DTC in Nigeria ${ }^{10}$, and the $\mathrm{USA}^{31}$ in which their main aim is drug formulary development and management. Two main factors may explain the limitation in the function of DTC in Sierra Leone. Firstly, this was a piloted program that is focused mainly to promoting rational medicine use at the hospital level; therefore, a complex mix of aims will be ambiguous and farfetched in a donor-driven healthcare system like Sierra Leone. Secondly, highly skilled healthcare professionals are few in Sierra Leone ${ }^{38}$, and those available are mostly demotivated ${ }^{39}$; hence a narrow scope is essential for success.

Key DTC indicators in Sierra Leone

DTC's success is, in part, dependent on effective planning, the establishment of feasible terms of reference and guidelines, which should include continuous training and readily available educational resources ${ }^{6}$. The majority of hospitals reported establishing these parameters; nonetheless, few are still on the process of doing so, and an account of their effectiveness cannot be verified.

\section{Subcommittees}

It is common practice for DTC to be fragmented into subcommittees tasked with specific specialized roles and responsibilities in line with its primary overall aim ${ }^{6,9,23}$. These subcommittees may vary considerably across jurisdictions and hospitals based on the general scope of the DTC ${ }^{29,30,32,40}$. Although some of the sub-committees are believed to be inefficient, nonfunctional, and inactive, in Sierra Leone, there are only two reported subcommittees in all hospitals, antimicrobial stewardship, and ADR subcommittee. The existence of these two subcommittees might be directly linked to WHO and PBSL's longstanding collaboration with hospitals ${ }^{41}$. This is found to be similar to other DTC elsewhere ${ }^{9}$ but different from what is obtains in Nigeria. DTCs in Nigeria, are known to have subcommittees on infection control, operational guideline, and quality assurance of medicines in addition to antimicrobial stewardship, and $\mathrm{ADR}^{10}$.

DTC meetings

The frequency of meetings reported in this study is similar to that reported in a South African study in which most meetings are held once a month and a few quarterly ${ }^{9}$. Nevertheless, it differs from findings in Nigeria ${ }^{10}$. Therefore, it may be sufficient to argue that the frequency of meetings varies considerably 
from country to country and from hospital to hospital. DTC meetings have been reportedly held bimonthly, monthly, quarterly, when necessary, or no meetings in some setting depending on the scope and mandate of DTC $24,32,42-44$. Notwithstanding these variations, a successful meeting required a clear agenda and the attendance of key members like the chairperson and secretary of DTC ${ }^{45}$. In doing so, it signals the importance of the meeting to other members, ensures the seriousness of proceedings, proper record keeping through active minutes taking, which inform better decision making ${ }^{31}$.

\section{Drug use policies, their implication, and unforeseen challenges}

The introduction of local drug use policies (Table 4) by members of the DTC may be regarded as a great leap, and perhaps so-far the most tangible measure towards rational medicines use at the hospital level. Such policies might be useful and achieve its purpose if they were formulated based on data from routine drug use evaluation, if there is no conflict of interest among members, and lastly if there is a consensus among all members in policy formulation, process ${ }^{24}$. An unbiased data-driven approach and inclusivity of the inputs of all members enhance adherence to the policy in that key heads of departments within the hospital are spear-heading the process; hence their subordinates will likely comply. A significant but commonly neglected practice is the documentation and monitoring of the impact of the new policy introduced ${ }^{37}$. The WHO and United Nations agencies, in collaboration with MSH and USAID ${ }^{6,7,23}$, have published manuals that provide stepwise instruction towards introducing and managing new drug use policies in a DTC.

\section{Opportunities and challenges of DTC in Sierra Leone}

DTC presents a subtle yet rare opportunity in ensuring rational medicines use at the hospital level in Sierra Leone. Generalized rational medicines use strategies or interventions introduced by governments are not always effective as intended in that each hospital has its specific root cause unique to them. DTC, therefore, is advantaged with assessing irrational medicines use problems specific to a hospital and formulating targeted policies towards their problems. There might be higher chances for success in policies introduced due to multidisciplinary inclusivity of local healthcare providers and heads of hospital units who are also members of DTC and can influence their peers and subordinates.

Amid the opportunities presented, the results highlight significant challenges within almost all DTC in Sierra Leone, which must be overcome for effectiveness to be realized. Among the challenges reported, the nonavailability of resources is classified as the most important and needs immediate intervention. Resources limitations represented a foreseeing challenge as do most interventions in the healthcare system in Sierra Leone, due to its reliance on donor funding ${ }^{3}$. Resources in this context are not limited to funding but encompass equipment, office space, educational materials, and human resource.

\section{Going forward towards effective DTC in Sierra Leone}

The future of DTC is difficult to predict; nonetheless, there are tangible yet subjective suggestions from both the literature and by pharmacists on ways to improving DTC in Sierra Leone. For instance, despite differences in setting and complexity, Mandy C et al.made a critical analysis of DTC management strategies to maximize output. They proposed that the attendance to meetings, sensitivity to timeline for policies and interventions, an appeal process that criticises all decision processes, and lastly, the implementation of decisions should be holistic and involve all members for optimal output of DTC ${ }^{44}$. Additionally, providing the resources needed for DTC operations, capacity building among members of DTC, governance, monitoring, and evaluation are suggestions put forward by pharmacists in Sierra Leone

Going forward, DTC functions may evolve to include medicines selections and procurements, and as such protocol on the selection of new medications to be added to a local formulary and how a conflict of interest issues are handled will dictate it fit for purpose and success ${ }^{46,} 47$.

\section{Limitations and strength}

Readers should interpret these findings with caution, noting the following limitations. This study employs a mixed-method approach highlighting the first detailed account of pilot DTC in Sierra Leone. Nonetheless, 
the results presented are the views of only hospital pharmacists, serving as secretary of the various DTCs in Sierra Leone. The account and experience of other members of DTC may be different and hence require evaluation in order to have a comprehensive insight on the topic under investigation. Also, the sample size is relatively small for both qualitative and quantitative aspects, and a non-probability sampling method was used to recruit participants. Therefore, the generalization of study results beyond this setting may not be feasible. This is perhaps the best possible approach since this study is descriptive, and DTC was only piloted in seven hospitals nationwide.

\section{Conclusion}

DTC pilot program was introduced with the primary aim of promoting medicines management and to reduce irrational medicines use in Sierra Leon. Evidence shows that DTC can be useful towards that end. Some hospital DTC made considerable progress through the introduction of policies and practices that promotes effective medicines, use, rational prescribing, and better patients' medication management. Except for a few, the majority of members expressed interest in DTC in Sierra Leone. Nevertheless, challenges need to be overcome for better optimization of the program nationally. DTC funding and operational resources, stand out as the most important limitation followed by technical competence of members. Therefore, policymakers

must note these drawbacks and formulate effective interventions towards addressing them whilst expanding DTC programs to other hospitals in Sierra Leone.

\section{Acknowledgement}

Many thanks to all hospital pharmacists that help support this project. We also want to thank Pharm Janet Burke for providing detailed information on DTC establishment in Sierra Leone, which helped in designing in this study.

\section{Conflict of interest statement}

No conflict of interest

\section{Authorship}

All authors made contributions in the conceptualization, design, analysis and interpretation of the data. JAK YF, PBJ, CK, JC, SX and MMK collected the data the study. The first draft was written by JAK, YF, SX, MMK, AS, PBJ and URM, which was critically appraised by all authors. All authors read and approve the final submitted version of the manuscript. JAK and MMK should be considered as first authors.

\section{Funding information}

This work was funded by the "Young Talent Support Plan," "High Achiever Plan" of Health Science Center, Xi'an Jiaotong University, and the Central University Basic Research Fund (2015qngz05).

\section{Data availability statement}

The data that support the findings of this study are available on request from the corresponding author. The data are not publicly available due to privacy or ethical restrictions.

\section{Reference}


1. WHO. Promoting rational use of medicines: core components. September, 2002.http://archives.who.int/tbs/rational/h3011e.pdf. Accesses September 6, 2020

2. Ofori-Asenso R, Brhlikova P, Pollock AM. Prescribing indicators at primary health care centers within the WHO African region: a systematic analysis (1995-2015). BMC public health. Aug 22 2016;16:724. doi:10.1186/s12889-016-3428-8

3. Witter S, Jones A, Ensor T. How to (or not to) ... measure performance against the Abuja target for public health expenditure. Health policy and planning . 2013;29(4):450-455. doi:10.1093/heapol/czt031 $\% \mathrm{~J}$ Health Policy and Planning

4. WH Organization. WHO Methodology for Point Prevalence Survey on Antibiotic Use in Hospitals, version 1.1. 2018.https://apps.who.int/iris/bitstream/handle/10665/280063/WHO-EMP-IAU2018.01-eng.pdf?ua=1. Accessed March 15, 2020.

5. Tonkin-Crine S, Knox K. Changing the antibiotic prescribing behaviour of clinicians in primary care. CMAJ : Canadian Medical Association journal = journal de l'Association medicale canadienne. Feb 2 2016;188(2):94-5. doi:10.1503/cmaj.151103

6. WH Organization. Drug and therapeutics committees: a practical guide. 2003.https://apps.who.int/iris/bitstream/handle/10665/68553/WHO_EDM_PAR_2004.1.pdf. Accessed January 252020.

7. Health MSf, Organization WH. Drug and Therapeutics Committee Training Course. Submitted to the US Agency for International Development by the Rational Pharmaceutical Management Plus Program. Management Sciences for Health Arlington, VA; 2007.https://www.who.int/medicines/technical_briefing/tbs/Participant-s-Guide-All-Sessions.pdf. Accessed September 6, 2020.

8. Weekes LM, Brooks C. Drug and Therapeutics Committees in Australia: expected and actual performance. British journal of clinical pharmacology . Nov 1996;42(5):551-7. doi:10.1111/j.13652125.1996.tb00048.x

9. Matlala M, Gous AG, Godman B, Meyer JC. Structure and activities of pharmacy and therapeutics committees among public hospitals in South Africa; findings and implications. Expert review of clinical pharmacology . Nov 2017;10(11):1273-1280. doi:10.1080/17512433.2017.1364625

10. Fadare JO, Ogunleye O, Obiako R, et al. Drug and therapeutics committees in Nigeria: evaluation of scope and functionality. Expert review of clinical pharmacology . Dec 2018;11(12):1255-1262. doi:10.1080/17512433.2018.1549488

11. Cole CP, James PB, Kargbo AT. An evaluation of the prescribing patterns for under-five patients at a Tertiary Paediatric Hospital in Sierra Leone. Journal of basic and clinical pharmacy . Sep 2015;6(4):109-14. doi:10.4103/0976-0105.168051

12. Kabba JA, Tadesse N, James PB, et al. Knowledge, attitude and antibiotic prescribing patterns of medical doctors providing free healthcare in the outpatient departments of public hospitals in Sierra Leone: a national cross-sectional study. 2020;

13. Lakoh S, Adekanmbi O, Jiba DF, et al. Antibiotic use among hospitalized adult patients in a setting with limited laboratory infrastructure in Freetown Sierra Leone, 2017-2018. International Journal of Infectious Diseases . 2020/01/01/2020;90:71-76. doi:https://doi.org/10.1016/j.ijid.2019.10.022

14. Leski TA, Taitt CR, Bangura U, et al. High prevalence of multidrug resistant Enterobacteriaceae isolated from outpatient urine samples but not the hospital environment in Bo, Sierra Leone. journal article. April 18 2016;16(1):167. doi:10.1186/s12879-016-1495-1

15. Leski TA, Bangura U, Jimmy DH, et al. Multidrug-resistant tet(X)-containing hospital isolates in Sierra Leone.International journal of antimicrobial agents . 2013/07/01/ 2013;42(1):83-86. doi:https://doi.org/10.1016/j.ijantimicag.2013.04.014

16. Witter S, Namakula J, Wurie H, et al. The gendered health workforce: mixed methods analysis from four fragile and post-conflict contexts.Health policy and planning . 2017;32(suppl_5):v52-v62. doi:10.1093/heapol/czx102 \%J Health Policy and Planning

17. Hamilton D, Bugg I. Improving antimicrobial stewardship in the outpatient department of a district general hospital in Sierra Leone.BMJ Open Qual . 2018;7(4):e000495-e000495. doi:10.1136/bmjoq2018-000495 
18. Promoting Safe and Appropriate Medicine Use in Sierra Leone | Management Sciences for Health. 2020.https://www.msh.org/blog/2017/11/15/promoting-safe-and-appropriate-medicine-usein-sierra-leone. Accessed September 6, 2020

19. Strengthening the Pharmaceutical System in Sierra Leone after Ebola | SIAPS Program..http://siapsprogram.org/publication/strengthening-the-pharmaceutical-system-in-sierraleone-after-ebola. Accessed January 5, 2020.

20. Sanitation SLMoHa. Sierra Leone Basic Package of Essential Health Services 2015-2020. 2015.https://mohs2017.files.wordpress.com/2017/06/gosl_2015_basic-package-of-essential-healthservices-2015-2020.pdf. Accessed September 6, 2020.

21. Borycki EJIPiHI. Developing a Medical Records System at the Ola During Children's Hospital, Freetown, Sierra Leone. 2011;164:174.

22. Sawatsky AP, Ratelle JT, Beckman TJ. Qualitative Research Methods in Medical Education. Anesthesiology . Jul 2019;131(1):14-22. doi:10.1097/aln.0000000000002728

23. Guidelines for Implementation of Pharmaceutical and Therapeutics Committee in Gauteng Province 2013.http://siapsprogram.org/wp-content/uploads/2014/01/13-191-PTC-Guidelines-Gauteng-SAFINAL.pdf. Accessed September 6, 2020.

24. Duran-Garcia E, Santos-Ramos B, Puigventos-Latorre F, Ortega A. Literature review on the Structure and operation of Pharmacy and Therapeutics Committees. International journal of clinical pharmacy . Jun 2011;33(3):475-83. doi:10.1007/s11096-011-9501-6

25. Giordano V, Koch H, Godoy-Santos A, Dias Belangero W, Esteves Santos Pires R, Labronici P. WhatsApp Messenger as an Adjunctive Tool for Telemedicine: An Overview. Interactive journal of medical research. Jul 21 2017;6(2):e11. doi:10.2196/ijmr.6214

26. De Benedictis A, Lettieri E, Masella C, et al. WhatsApp in hospital? An empirical investigation of individual and organizational determinants to use. PloS one . 2019;14(1):e0209873. doi:10.1371/journal.pone.0209873

27. Thomas DR. A General Inductive Approach for Analyzing Qualitative Evaluation Data. 2006;27(2):237-246. doi:10.1177/1098214005283748

28. Lima-Dellamora Eda C, Caetano R, Gustafsson LL, Godman BB, Patterson K, Osorio-de-Castro CG. An analytical framework for assessing drug and therapeutics committee structure and work processes in tertiary Brazilian hospitals. Basic 83 clinical pharmacology 8 toxicology . Sep 2014;115(3):268-76. doi: $10.1111 /$ bcpt. 12215

29. Alefan Q, Alshareef S, Al-Shatnawi S. Drug and therapeutics committees in Jordanian hospitals: a nationwide survey of organization, activities, and drug selection procedures. Pharmacy practice . Oct-Dec 2019;17(4):1590. doi:10.18549/PharmPract.2019.4.1590

30. Plet HT, Hallas J, Nielsen GS, Kjeldsen LJ. Drug and therapeutics committees in Danish hospitals: a survey of organization, activities and drug selection procedures. Basic $\&$ clinical pharmacology $\&$ toxicology . Apr 2013;112(4):264-9. doi:10.1111/bcpt.12028

31. Mannebach MA, Ascione FJ, Gaither CA, Bagozzi RP, Cohen IA, Ryan ML. Activities, functions, and Structure of pharmacy and therapeutics committees in large teaching hospitals. American journal of health-system pharmacy : AJHP : official journal of the American Society of Health-System Pharmacists . Apr 1 1999;56(7):622-8. doi:10.1093/ajhp/56.7.622

32. Puigventós F, Santos-Ramos B, Ortega A, Durán-García E. Structure and procedures of the pharmacy and therapeutic committees in Spanish hospitals. Pharmacy world \&s science : PWS . Dec 2010;32(6):767-75. doi:10.1007/s11096-010-9435-4

33. Hoffmann M. The right drug, but from whose perspective? A framework for analyzing the Structure and activities of drug and therapeutics committees. European journal of clinical pharmacology. May 2013;69 Suppl 1:79-87. doi:10.1007/s00228-013-1491-y

34. Weekes LM, Brooks C, Day RO. Indicators for Drug and Therapeutics Committees. 1998;45(4):393-398. doi:10.1046/j.1365-2125.1998.t01-1-00699.x

35. Penm J, Chaar B, Dechun J, Moles R. Formulary systems and pharmacy and therapeutics committees in the Western Pacific Region: exploring two Basel Statements. American journal of health-system 
pharmacy : AJHP : official journal of the American Society of Health-System Pharmacists . Jun 1 2013;70(11):967-79. doi:10.2146/ajhp120396

36. Hoffmann M. The right drug, but from whose perspective? A framework for analyzing the Structure and activities of drug and therapeutics committees. European journal of clinical pharmacology. May 2013;69 Suppl 1(Suppl 1):79-87. doi:10.1007/s00228-013-1491-y

37. Mashaba TP, Matlala M, Godman B, Meyer JC. Implementation and monitoring of decisions by pharmacy and therapeutics committees in South African public sector hospitals. Expert review of clinical pharmacology . Feb 2019;12(2):159-168. doi:10.1080/17512433.2018.1545572

38. Sanitation GoSLMoHa. Annual Health Sector Performance Report 2016 . 2016.http:/www.afro.who.int/sites/default/files/2017-08/Sierra\%20Leone\%20Health\%20Sector\%20\%20Performance\%

39. Bertone MP, Lagarde M. Sources, determinants and utilization of health workers' revenues: evidence from Sierra Leone. Health policy and planning . 2016;31(8):1010-1019. doi:10.1093/heapol/czw031 \%J Health Policy and Planning

40. Anagnostis E. Writing meeting minutes for a pharmacy and therapeutics committee and its subcommittees. American journal of health-system pharmacy : AJHP : official journal of the American Society of Health-System Pharmacists . Jan 15 2015;72(2):95-6, 98-9. doi:10.2146/ajhp130639

41. Abiri OT, Johnson WCN. Pharmacovigilance systems in resource-limited settings: an evaluative case study of Sierra Leone. Journal of pharmaceutical policy and practice . 2019/06/11 2019;12(1):13. doi:10.1186/s40545-019-0173-2

42. Fijn R, Brouwers JR, Knaap RJ, De Jong-Van Den Berg LT. Drug and Therapeutics (D \& T) committees in Dutch hospitals: a nationwide survey of Structure, activities, and drug selection procedures.British journal of clinical pharmacology . Aug 1999;48(2):239-46. doi:10.1046/j.13652125.1999.00001.x

43. Schiff GD, Tripathi JB, Galanter W, et al. Drug formulary decision-making: Ethnographic study of 3 pharmacy and therapeutics committees. American journal of health-system pharmacy : AJHP : official journal of the American Society of Health-System Pharmacists . Apr 8 2019;76(8):537-542. doi:10.1093/ajhp/zxz022

44. Leonard MC, Thyagarajan R, Wilson AJ, Sekeres MA. Strategies for success in creating an effective multihospital health-system pharmacy and therapeutics committee. American journal of health-system pharmacy : AJHP : official journal of the American Society of Health-System Pharmacists . Apr 1 2018;75(7):451-455. doi:10.2146/ajhp170531

45. Mikkelsen CM, Andersen SE. A Regional Drug and Therapeutics Committee-led Intervention to Reduce the Hospital Costs of Expensive HIV Drugs. Basic 83 clinical pharmacology 85 toxicology . Sep 2016;119(3):278-83. doi:10.1111/bcpt.12585

46. Perrone J, Nelson LS. Pharmacy and therapeutics committees: leadership opportunities in medication safety for medical toxicologists. Journal of medical toxicology : official journal of the American College of Medical Toxicology . Jun 2011;7(2):99-102. doi:10.1007/s13181-011-0147-5.

47. Shah N. Managing potential conflicts of interest in state Medicaid pharmacy and therapeutics committees: seeking harmony. JAMA Intern Med . Mar 11 2013;173(5):344. doi:10.1001/jamainternmed.2013.4184.

Table 1 : Membership of drug and therapeutics committee

\section{Designation}

\section{Secondary}

hospital 1

Regional

hospital 1

Regional 
hospital 2

\section{Regional}

hospital 3

Regional

hospital 3

Tertiary

hospital1

Tertiary

hospital1

Tertiary

hospital2

1

The chairperson of DTC

Doctor

Doctor

Doctor

Doctor

Doctor

Doctor

Doctor

Doctor

2

The secretary of DTC

Pharmacist

Pharmacist

Pharmacist

Pharmacist

Pharmacist

Pharmacist

Pharmacist

Pharmacist

3

Pharmacists

2 
More than 3

3

4

\section{Doctors}

3

3

More than 3

More than 3

3

3

3

More than 3

5

Nurses

1

3

2

2

3

3

4

4

6

Microbiologist (Lab technician)

None

1

2

2

1 
Community health officer(s) (CHO)

None

1

1

1

1

1

2

1

8

Hospital financial department

None

1

None

None

None

None

None

None

9

Hospital administrative department

None

2

1

1

1

1

1

1

10 


\section{Technical support personnel from MoHS/WHO/MSH}

None

1

None

None

1

1

1

1

11

Others

None

Physiotherapist

ETAT Pediatrician

ETAT Pediatrician

$\mathrm{M} \& \mathrm{E}$,

$\mathrm{M} \& \mathrm{E}$,

None

None

IPC focal

IPC focal

DTC: Drug and therapeutic committee; ETAT: Emergency triage, assessment, and treatment. M\&E: Monitoring and evaluation. IPC: Infection prevention and control. MoHS: Ministry of health and sanitation

Table 2: Main functions of drug and therapeutic committee in different hospitals

\section{Function}

\section{Secondary}

hospital 1

Regional

hospital 1

\section{Regional}

hospital 2

Tertiary

hospital 1

Tertiary

hospital 2 


\section{Tertiary}

hospital 3

Promote rational medicines usage in the hospital

Yes

Yes

Yes

Yes

Yes

Yes

Monitor, document, and report adverse drug reactions/events

Yes

Yes

Yes

Yes

Yes

Yes

Provide drug information supports to hospital staffs

Yes

Yes

Yes

Yes

Yes

Yes

Antimicrobial stewardship

Yes

Yes

Yes

Yes

Yes

Yes

Prevention of drug shortages

No

Yes

Yes 
No

Yes

Yes

Drug Procurements

No

Yes

No

No

No

No

Indicators

Secondary

hospital 1

\section{Regional}

hospital 1

Regional

hospital 2

Tertiary

hospital 1

Tertiary

hospital 2

Tertiary

hospital 3

Does your DTC have a stated mission, terms of reference, and annual plan?

Yes

No

Yes

No

Yes

Yes

Does the DTC annual plan include capacity building activities (workshops, seminars, or continuing education)?

Yes

Yes

Yes 
Yes

Yes

Yes

Are there educational resources or activities available for DTC members to develop their role in the committee?

Yes

No

Yes

Yes

Yes

No

Does the DTC have subcommittees

Yes

Yes

Yes

Yes

Yes

Yes

Is there a Sub-committee on Antimicrobials audit within your DTC?

Yes

Yes

Yes

No

Yes

Yes

Does your DTC have standard guidelines and well-established working procedures within the hospital?

Yes

Yes

Yes

No

Yes

Yes

Does the DTC has allocated funds for its activities?

No

No 
No

Not sure

No

No

Does the DTC have authority to make decisions on the use of drugs in the hospital?

Yes

Yes

Yes

No

Yes

Yes

Does your DTC participate in making recommendations on procurement of medicines at your hospital?

Yes

Yes

Yes

No

Yes

Yes

Does your DTC periodically monitor medicines use within your hospital?

Yes

Yes

Yes

No

Yes

Yes

Does the DTC review cases of medication errors?

Yes

Yes

Yes

No

Yes

Yes

Does your DTC have a protocol for ADR/ADEs reporting?

Yes 
Yes

Not sure

No

Yes

No

Frequency of DTC meetings

Quarterly

Quarterly

Quarterly

Monthly

Monthly

Monthly

Last DTC meeting was on

Feb 2020

Jan 2020

Jan 2020

July 2019

Feb 2020

Feb 2020

Number of DTC meetings held in the past twelve months

1

3

3

1

8

4

Number of copies of ADR reports recorded in the last 12 months

None

16

2

None

5

10

Proportion of DTC members who attended the last meetings? 
$>50 \%$

$>50 \%$

$>50 \%$

$<50 \%$

$>50 \%$

$>50 \%$

Proportion of DTC policy decisions that have been implemented in past 12 months?

Some

Some

Some

None

All

some

Number of drug use policy submissions approved by DTC for Implementation

Some

Some

Some

None

None

Some

Proportion of decisions clearly documented

Some

Some

Some

None

Some

Some

On a scale of $1-10,1$ being "not effective" and 10 being "extremely effective" how will you rate the effectiveness of your hospital's DTC?

5

7

6

1

5 
Table 3: Key indicators of drug and therapeutic committee in different hospitals

Table 4: Drug use policies introduced in some hospitals and their impact on rational medicines used

\begin{tabular}{|c|c|c|c|c|}
\hline $\begin{array}{l}\text { Drugs with a } \\
\text { high } \\
\text { prescription } \\
\text { rate }\end{array}$ & $\begin{array}{l}\text { Patients } \\
\text { category } \\
\text { affected }\end{array}$ & $\begin{array}{l}\text { Reason for } \\
\text { irrational use } \\
\text { or practice }\end{array}$ & $\begin{array}{l}\text { Local policy } \\
\text { introduces }\end{array}$ & $\begin{array}{l}\text { Success and } \\
\text { challenges since } \\
\text { the } \\
\text { introduction of } \\
\text { the policy }\end{array}$ \\
\hline Paracetamol tablet & Pregnant women & $\begin{array}{l}\text { Prescribe } \\
\text { paracetamol as an } \\
\text { incentive for } \\
\text { patients' patronage } \\
\text { with FHC services }\end{array}$ & $\begin{array}{l}\text { All medicines must } \\
\text { be prescribed only if } \\
\text { clinically needed by } \\
\text { patients. }\end{array}$ & $\begin{array}{l}\text { A substantial } \\
\text { decrease in the rate } \\
\text { of paracetamol } \\
\text { prescribing over } \\
\text { time. Sustainability } \\
\text { might be a challenge }\end{array}$ \\
\hline Nystatin syrup & Children under five & $\begin{array}{l}\text { When under-five } \\
\text { children have } \\
\text { present with white } \\
\text { patches in the } \\
\text { mouth }\end{array}$ & $\begin{array}{l}\text { The clinicians must } \\
\text { establish the } \\
\text { possible existence of } \\
\text { a fungal infection. }\end{array}$ & $\begin{array}{l}\text { A decrease in } \\
\text { Nystatin prescribing } \\
\text { rate. Laboratory } \\
\text { diagnosis of fungal } \\
\text { infection is a } \\
\text { challenge }\end{array}$ \\
\hline $\begin{array}{l}\text { Artemether and } \\
\text { lumefantrine (FDC) }\end{array}$ & $\begin{array}{l}\text { Pregnant women, } \\
\text { lactating mothers, } \\
\text { and children under } \\
\text { five }\end{array}$ & $\begin{array}{l}\text { Patients presenting } \\
\text { with high body } \\
\text { temperature were } \\
\text { prescribed } \\
\text { antimalarial } \\
\text { without definitive } \\
\text { laboratory diagnosis }\end{array}$ & $\begin{array}{l}\text { Dispensed only if } \\
\text { there is an } \\
\text { accompanying } \\
\text { positive lab report }\end{array}$ & $\begin{array}{l}\text { A reduction in the } \\
\text { rate of antimalaria } \\
\text { prescribing. } \\
\text { Sustainability of the } \\
\text { policy might be a } \\
\text { challenge }\end{array}$ \\
\hline $\begin{array}{l}\text { Amoxicillin syrup } \\
\text { tablets Or capsules }\end{array}$ & All patients & $\begin{array}{l}\text { All patients with } \\
\text { signs of upper } \\
\text { respiratory } \\
\text { infection. }\end{array}$ & $\begin{array}{l}\text { Not more than one } \\
\text { antibiotic on a } \\
\text { patient's } \\
\text { prescription }\end{array}$ & $\begin{array}{l}\text { Decrease wastage of } \\
\text { medicines and } \\
\text { unnecessary use of } \\
\text { antibiotics }\end{array}$ \\
\hline $\begin{array}{l}\text { Prescription } \\
\text { leaflets }\end{array}$ & All patients & $\begin{array}{l}\text { Non-prescribers } \\
\text { without the legal } \\
\text { framework use to } \\
\text { prescribed for } \\
\text { patients }\end{array}$ & $\begin{array}{l}\text { All prescriptions } \\
\text { must come from } \\
\text { doctors, CHO or } \\
\text { healthcare } \\
\text { provider with the } \\
\text { legal framework } \\
\text { and competence }\end{array}$ & $\begin{array}{l}\text { Preventions of } \\
\text { medication errors, } \\
\text { and wastage of } \\
\text { medicines }\end{array}$ \\
\hline Prescription & All patients & $\begin{array}{l}\text { Some healthcare } \\
\text { providers } \\
\text { prescribing on } \\
\text { any leaflets }\end{array}$ & $\begin{array}{l}\text { All prescriptions } \\
\text { must be written } \\
\text { on the hospital } \\
\text { provided } \\
\text { prescription } \\
\text { leaflets before } \\
\text { drugs can be } \\
\text { dispensed. }\end{array}$ & $\begin{array}{l}\text { Reduction in } \\
\text { prescriptions with } \\
\text { errors and } \\
\text { medicines wastage }\end{array}$ \\
\hline
\end{tabular}




\begin{tabular}{|c|c|c|c|c|}
\hline $\begin{array}{l}\text { Drugs with a } \\
\text { high } \\
\text { prescription } \\
\text { rate }\end{array}$ & $\begin{array}{l}\text { Patients } \\
\text { category } \\
\text { affected }\end{array}$ & $\begin{array}{l}\text { Reason for } \\
\text { irrational use } \\
\text { or practice }\end{array}$ & $\begin{array}{l}\text { Local policy } \\
\text { introduces }\end{array}$ & $\begin{array}{l}\text { Success and } \\
\text { challenges since } \\
\text { the } \\
\text { introduction of } \\
\text { the policy }\end{array}$ \\
\hline Prescription & $\begin{array}{l}\text { Under-five } \\
\text { children }\end{array}$ & $\begin{array}{l}\text { Effective dosage } \\
\text { calculation in an } \\
\text { instance where } \\
\text { the prescribers } \\
\text { omit dosage. }\end{array}$ & $\begin{array}{l}\text { The weight of the } \\
\text { child must be } \\
\text { written in all } \\
\text { prescriptions for } \\
\text { children under } \\
\text { the age of five. }\end{array}$ & $\begin{array}{l}\text { Help prevent } \\
\text { overdosing and } \\
\text { drug toxicities }\end{array}$ \\
\hline
\end{tabular}

FDC: Fixed drug combination; CHO: Community health workers

Table 5: Main challenges towards the effective functioning of DTC in Sierra Leone

\begin{tabular}{ll}
\hline Challenges $(\mathbf{n}=\mathbf{6})$ & Explanation \\
\hline Limited resources to maintaining the DTC $(\mathrm{n}=6)$ & No funds for maintaining DTC \\
Implementation of DTC decisions $(\mathrm{n}=4)$ & Some Clinicians think DTC is a witch-hunt Lack of tech \\
Unmotivated DTC member $(\mathrm{n}=4)$ & Difficulties in implementing drug use policies No refresh \\
Some members are not quite interested $(\mathrm{n}=3)$ & Added responsibilities with no extra income \\
Meetings are not well attended $(\mathrm{n}=1)$ & The meeting coincides with other tasks and responsibili \\
DTC activities are not well recognized within the hospital $(\mathrm{n}=2)$ & Prescribers do not wish to be censored. Superiority com \\
Members of the DTC lack technical training $(\mathrm{n}=3)$ & No effective mentorship or in-house training \\
Others $(\mathrm{n}=2)$ & Conflict of interest No office space \\
\hline
\end{tabular}

